\title{
EDITORIAL V16 N2 (2021)
}

Esta nova edição da Gestão \& Tecnologia de Projetos em fluxo contínuo [v.16, n.2., 2021] apresenta artigos representativos do perfil e da diversidade de temas da Revista, com entrelaçamentos importantes entre as áreas de arquitetura, engenharia e design.

Também demonstra artigos apoiados em pesquisas realizadas por grupos sediados no Rio Grande do Sul, Santa Catarina, Paraná, São Paulo, Rio de Janeiro, Pernambuco e Rio Grande do Norte. Estas pesquisas, bases dos artigos presentes neste número, tem forte presença de pósgraduandos, na maioria apoiados por Agências de Fomento de âmbito federal, mas também, em alguns casos, de âmbito estadual.

Nota-se, ainda, crescente preocupação dos autores com o compromisso com a ética na pesquisa, pois vários destes estudos foram realizados em parte com interações com seres humanos, na forma de aplicação de questionários, realização de entrevistas e de oficinas.

É neste contexto que os artigos vinculados à gestão do processo de projeto e temas afins mostram a robustez e os resultados das pesquisas na área. São pesquisas no campo digital, dos ensaios físicos, das revisões sistemáticas da literatura, sobre teoria e inovação e relativamente às experimentações no ensino/aprendizagem em arquitetura e engenharia (estruturas).

Diversos artigos, enfatizam os estudos sobre Modelagem da Informação da Construção (BIM), a saber, aqueles de autoria de Côco e Celani intitulado "Algoritmização do projeto arquitetônico em BIM"; de autoria de Andrade, Biotto e Serra, denominado "Modelagem BIM para orçamentação com uso do SINAPI" e o de autoria de Lima, Catai e Scheer sob o título "Análise de modelos de maturidade para medição da implementação do Building Information Modeling (BIM).

O 5ํartigo desta edição, de autoria de Côco e Celani, discute o emprego da Modelagem da Informação da Construção e dos algoritmos no processo de projeto de arquitetura e apresenta procedimento para integrar essas duas tecnologias, em uma aplicação na área da construção industrializada de banheiros. 0 método de pesquisa utilizado foi exploratória e contemplou o desenvolvimento de software em uma abordagem baseada em regras para a geração automatizada de layouts de banheiros. Os resultados demonstraram o potencial dos algoritmos de definição de regras na eliminação de trabalhos repetitivos e prevenção de erros de montagem.

No 60 artigo desta edição, de autoria de Andrade, Biotto e Serra, realizou-se um estudo sobre a aplicação do BIM para obtenção de quantitativos e precificação vinculada com as especificações do Sistema Nacional de Pesquisa de Custos e Índices da Construção Civil (SINAPI). 0 método de estudo foi uma obra vinculada ao setor público. Foram verificadas semelhanças entre quantitativos extraídos do modelo BIM com o processo manual e tradicional para a licitação. Todavia, conforme demonstrado no artigo, para se utilizar os dados de custos do SINAPI seria necessário que o modelo fosse elaborado objetivando, especificamente, a orçamentação.

O $8^{\text {o }}$ artigo desta edição, de autoria de Lima, Catai e Scheer, analisa três modelos - BIM Assessment Profile, BIM Maturity Matrix e VDC Scorecard, para disseminar o uso dessas ferramentas. Como método de pesquisa foram adotados procedimentos comparativos e levantamentos de campo. Os resultados mostram que todas as ferramentas aferidas apresentam aspectos processuais, técnicos e de pessoas, possibilitando aferir, na prática, o grau de maturidade BIM das empresas e projetos avaliados. 
Outros três artigos apresentam estudos mais conceituais e teóricos. Um deles, de autoria de Barauna, Razera, Zamoner e Silva, sob o título "Design de materiais como uma demanda da ciência e tecnologia para a inovação" explora o futuro das ciências dos materiais; outro de Varnier, Fettermann e Merino denominado "Processo de desenvolvimento de produtos no vestuário: uma revisão sistemática de modelos de auxílio à prática projetual de produtos da moda" , realiza, sobre este tema, ampla revisão sistemática da literatura e, um terceiro, de autoria de Muianga e Granja intitulado "Estrutura conceitual do Integrated Project Delivery (IPD): princípios catalisadores e proposições" discute o potencial do modelo IPD para todo o processo de produção de um empreendimento, incluindo as etapas de contrato e de operação.

O 4o artigo desta edição, de autoria de Barauna, Razera, Zamoner e Silva, visa discutir o termo design de materiais mediante a promoção da inovação. Para tanto, foi adotado os procedimentos metodológicos, revisão sistemática da literatura e a análise de conteúdo. Como resultados, constatou-se que o design de materiais no século 21 , tem a intenção de ampliar com sucesso a difusão da inovação para a sociedade.

03 3o artigo desta edição, de autoria de Varnier, Fettermann e Merino, editado por S.W.Ornstein, pretende identificar os principais modelos desenvolvidos para auxiliar o processo de desenvolvimento de produtos de moda, por meio de uma revisão sistemática da literatura. Ou seja, foi possível identificar modelos que procuram aprimorar os processos de desenvolvimento de produtos de moda dando destaque para a pesquisa, criação e detalhamento, desenvolvimento, e a promoção e comercialização da linha de produtos.

O $10^{\circ}$ artigo desta edição, de autoria de Muianga e Granja, objetiva analisar e sintetizar a informação relacionada ao IPD, identificar as associações entre os seus elementos e desenvolver proposições que norteiam a sua aplicação. Como método de pesquisa, adotou-se aquela qualitativa e exploratória. Os resultados deste estudo apresentam a disposição dos elementos do IPD - e seus benefícios - nas diversas etapas de produção do empreendimento.

Já na busca das inovações para a construção civil, dois artigos buscam aliar o tema atual da responsabilidade e da avaliação ambiental com o ensino de projeto. Um deles, de autoria de Taparello, Luciano, Secchi e Vaz denomina-se "Arquitetura performativa: o uso de materiais responsivos e fabricação digital em experiência de ensino" e o segundo, de autoria de Caldas e Toledo Filho, denominado "Avaliação ambiental do sistema construtivo de alvenaria de blocos de solo-cimento considerando diferentes especificações de projeto".

$02^{\circ}$ artigo desta edição, de autoria de Taparello, Luciano e Secchi, explorou a madeira (uma estrutura em MDF) e seu potencial de uso como material responsivo em atividade de ensino de graduação em ateliê. A atividade junto a graduandos permitiu que estes compreendessem o comportamento do material, suas propriedades físicas e das tecnologias envolvidas com o seu processo de fabricação com vistas a sua aplicabilidade no projeto de arquitetura de um edifício submetido a diferentes contextos ambientais.

O 9o artigo desta edição, de autoria de Caldas e Toledo Filho, pretendeu avaliar os impactos ambientais no ciclo de vida de diferentes especificações de projeto do sistema de alvenaria estrutural de blocos de solo-cimento. Estes foram comparados com as alvenarias estruturais tradicionais de blocos cerâmicos e de concreto. Para tanto empregou-se a Avaliação do Ciclo de Vida (ACV). 0 estudo demonstrou para o caso brasileiro, o desempenho ambiental de diferentes alternativas do sistema de alvenaria de blocos de solo-cimento. 
Dois artigos enfatizam em especial os temas dos arcabouços normativo e legal abrangidos pela acessibilidade e pela NBR 15575. No caso da acessibilidade, tem-se o artigo de autoria de Rodrigues e de Bernardi intitulado "A Ampliação do conhecimento legal e técnico como estratégia para o desenvolvimento de projetos e ambientes" e no caso da NBR 15575, o artigo de autoria de Morais, Lordsleem e Andery sob o título "Implementação da norma de desempenho NBR 15575:2013: Estudo de caso em Recife/PE".

$01^{\text {o }}$ artigo desta edição, de autoria de Rodrigues e Bernardi, apresenta e discute os arcabouços legal e normativo relacionados à acessibilidade e ao desenho universal, a partir de uma pesquisa-ação abrangendo arquitetos e engenheiros envolvidos com estes temas. 0 artigo concluiu que os profissionais participantes da pesquisa passaram a compreender que a legislação e normas tem como foco o atendimento amplo às pessoas e não simplesmente $o$ atendimento a regulamentações de órgãos públicos.

$07^{0}$ artigo desta edição, de autoria de Morais, Lordsleem e Andery, editado por S.W.Ornstein, se propõe a demonstrar a partir de estudos de caso - empreendimentos situados em Recife/ PE quais as ações e estratégias necessárias para que o setor da construção civil local implemente a NBR 15575 no seu cotidiano, desde a análise de riscos, desenvolvimento do perfil de desempenho do empreendimento, formas de contratação e de compras, treinamento de equipes para execução e revisão de manuais de uso.

Um $11^{\circ}$ artigo, retoma o tema do ensino de projeto, porém sob a ótica da concepção estrutural, para edifícios de grande altura, temática pouco explorada enquanto atividade de ensino e pesquisa em escolas de arquitetura. É de autoria de Resende e Veloso. Denomina-se "O ensino da concepção estrutural no ateliê de projeto de edifícios verticais: um estudo de caso na Universidade Federal do Rio Grande do Norte".

Este último artigo, abre uma importante discussão sobre diversos métodos possíveis para ensino em ateliê de curso de graduação sobre o projeto de arquitetura verticalizado e sua relação com o sistema estrutural. Ressalta a relevância da integração entre as concepções arquitetônica e estrutural nas atividades de ensino / aprendizado de projeto, diferentemente das formas convencionais e, muitas vezes isoladas, do ensino de estruturas para graduandos em arquitetura.

Este conjunto de artigos nos permite inferir que existem avanços nos campos teóricos e metodológicos relativamente às pesquisas no campo da gestão do processo de projeto e busca robusta,,pelos autores de temáticas de estudo inovadoras e com possibilidade de aplicação na prática profissional e no cotidiano das atividades da construção civil.

Desejamos a todos uma excelente leitura!

Sheila Walbe Ornstein

Paulo Roberto Pereira Andery

Márcio Minto Fabricio

Editores 